\title{
Hypoxylon mammatum toxins: possible involvement in canker development on aspen
}

\author{
I. Genetet ${ }^{1}$, J. Pinon 1 , B. Bodo ${ }^{2}$ and S. Rebuffat ${ }^{2}$ \\ 1 Laboratoire de Pathologie Forestière, INRACRF, Champenoux F-54280, Seichamps, and \\ 2 Muséum National d'Histoire Naturelle, Chimie Appliquée aux Corps Organisés, CNRS UA401, 63, \\ rue Buffon, F-75231 Paris Cedex 05, France
}

\section{Introduction}

Hypoxylon mammatum (Wahl.) Miller causes a stem canker on aspen (Populus tremula) and on some poplars of the Tacahamaca section (Pinon, 1976). The disease is characterized by a flattened sunken surface with a yellow orange margin. H. mammatum prevents host callusing. Hubbes (1964) found that diffusible substances from $H$. mammatum agar cultures inhibited callus formation in wounds on aspen bark. Schipper (1978) and Stermer et al., (1984) confirmed the possibility that $H$. mammatum could produce toxins. These compounds can be isolated by partitioning into various organic solvents and chromatography. Culture age was also supposed to affect the kind and amount of metabolites produced (Stermer et al., 1984). We have isolated and characterized 2 groups of toxins from culture filtrate (Bodo et al., 1987). Optimum secretion was achieved within 6 wk of still culture on wort medium. A technique has been developed to isolate the toxins from the filtrate by adsorption onto a neutral resin (Amberlite XAD 4). Two groups of toxins were separated by elution of the XAD resin with a methanol/water gradient: hymatoxins first eluted (about $40 \mathrm{mg} / \mathrm{l}$ of filtrate) and then neutral metabolites (a few $\mathrm{mg} / \mathrm{l})$. The chemical structures of these substances were determined by spectrometric methods (MS, IR, 1D and 2D NMR). Hymatoxins are unusual diterpene sulfates with a molecular mass of about 400 . The other toxin group is constituted of trihydroxytetralones.

To provide a clearer understanding of the pathotoxic features of $\mathrm{H}$. mammatum, search for and characterization of in vivo toxic metabolites were undertaken and the data are reported herein.

\section{Materials and Methods}

\section{Purification procedure}

Young aspen trees were obtained from breeding programs (Lemoine, 1973). The trees were planted and inoculated with mycelium in 1981 (Pinon et al., 1988). After $6 \mathrm{yr}$, the H. mammatum trees were cut. Wood and bark samples from both healthy and infected areas were collected. Each sample was freeze-dried, ground and then kept at $-20^{\circ} \mathrm{C}$. $100 \mathrm{~g}$ of each sample 
were extracted in a soxhlet apparatus with methanol for $6 \mathrm{~h}$. The extracts were concentrated and an aliquot of each sample was tested for its toxicity using a leaf bioassay. The active extracts were partially purified by chromatography on Sephadex $\mathrm{LH}-20$. The fractions obtained were reduced to dryness under vacuum.

\section{Leaf bioassay}

Throughout the purification procedure, samples were bioassayed by determining their effects on the leaves according to Pinon (1984). The leaves were taken from clones obtained from in vitro cultures and grown in a greenhouse. After cutting, the leaf petiole was placed in small tubes containing the fraction to test. 5 or
10 leaves were taken for each assay. Acetone $(1 \%)$ was used as control.

\section{Results and Discussion}

When tested at a concentration of 1 $\mathrm{mg} / \mathrm{ml}$, extracts from healthy wood and bark samples had no visible effects, whereas those from infected wood and bark samples induced necrosis. However, the response was not as large with the wood extracts as compared to those of bark.
706.8
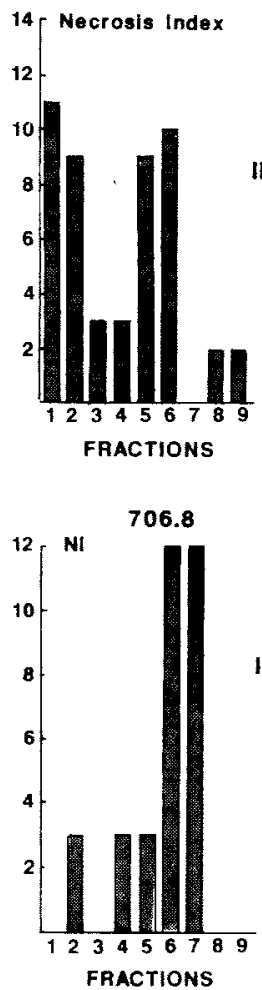

710.23
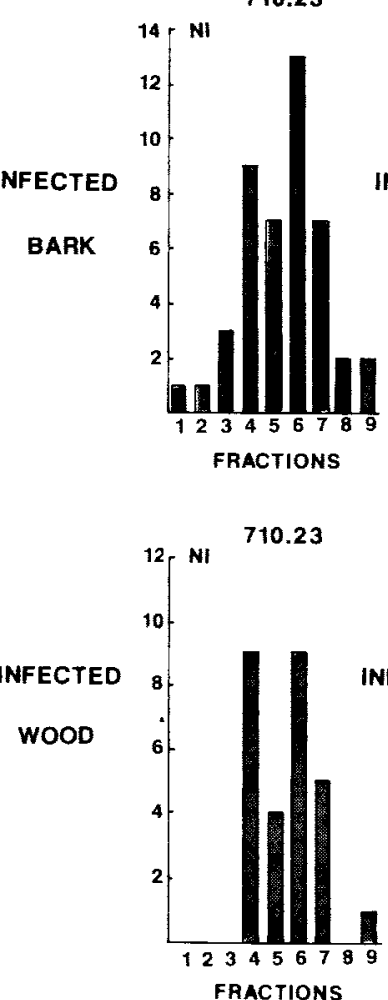

710.23

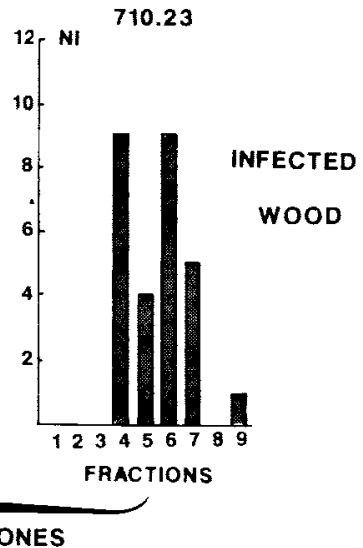

712.1
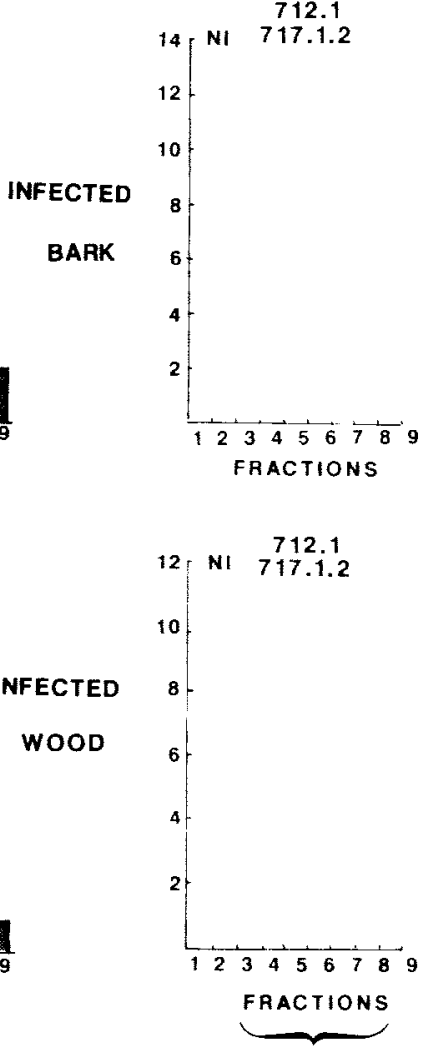

RESISTANT CLONES

Fig. 1. In vitro and in vivo sensitivity of some clones to toxins. 
Each toxic extract was separated into 9 fractions on Sephadex $\mathrm{LH}-20$. They were concentrated to dryness and $100 \mathrm{mg}$ of the concentrates were dissolved in $1 \mathrm{ml}$ of acetone, then completed to $100 \mathrm{ml}$ with distilled water. The fractions were bioassayed against 4 aspen clones which had been selected for their different behaviors under artificial inoculation: clones 717 . $1.2,712.1$ and 706.8 were susceptible and clone 710.23 was quite tolerant.

The 4 clones showed the same sensitivity to hymatoxins and to the toxic extracts from infected trees: no necrosis was observed with clones 717.1.2 and 712.1, whereas leaf necrosis was observed with clones 706.8 and 710.23 (Fig. 1).

Fractions 5 and 6 of the infected bark extract were always necrotic for these last two clones, but, in addition, fraction 1 was toxic for clone 706.8 and fraction 4 for clone 710.23. From all these results, it appears that 2 groups of toxins are present in the bark extract: one is eluted in the first fractions and the second in the middle fractions of Sephadex LH-20 chromatography. When analyzed by thin-layer chromatography, both toxic fractions were still too complex to enable identification of hymatoxins.

The most toxic fractions from the infected wood extracts were fractions 6 and 7. Each of these toxic fractions was subjected to silica gel chromatography in order to obtain simpler fractions, allowing the search for the in vivo toxins (hymatoxins, tetralones).

Most of the studies on toxins involved in H. mammatum canker were carried out with cultures of this fungus on synthetic medium. The precise role of the metabolites thus isolated in pathogenesis must be investigated. Our preliminary results demonstrated the presence of toxic substances in infected bark and wood from a freshly cut tree. These compounds have no effect on the clone known for its resistance to in vitro toxins.

Preliminary chemical examination of the complex toxic extract from infected bark does not enable us to conclude as to the presence or absence of hymatoxins and trihydroxytetralones.

\section{References}

Bodo B., Davoust D., Lecommandeur D., Rebuffat S., Genetet I. \& Pinon J. (1987) Hymatoxin $A$, a diterpene sulfate phytotoxin of Hypoxylon mammatum, parasite of aspen. Tetrahedron Lett. 28, 2355-2358

Hubbes M. (1964) New facts on host-parasite relationships in the Hypoxylon canker of aspen. Can. J. Bot. 42, 1489-1494

Lemoine M. (1973) Amélioration des peupliers de la section Leuce sur sols hydromorphes. Thèse, Université de Nancy I, France

Pinon J. (1976) Une menace grave pour les trembles alpins: le chancre à Hypoxylon mammatum. Rev. For. Fr. 28, 31-34

Pinon J. (1984) Propriétés biologiques de la toxine d'Hypoxylon mammatum, parasite des peupliers de la section Leuce. Rev. Cytol. Biol. Végét. Bot. 7, 271-277

Pinon J., Genetet I., Bodo B. \& Rebuffat S. (1988) Apport des vitrocultures à l'étude des métabolites secondaires d'origine fongique agissant sur le cambium des peupliers. $32 e$ Colloque de la Société française de Phytopathologie, Angers, 14-15 mai, ACTA, in press

Schipper A.L. Jr. (1978) A Hypoxylon mammatum toxin responsible for canker formation in quaking aspen. Phytopathology 68, 868-872

Stermer B.A., Scheffer R.P. \& Hart J.H. (1984) Isolation of toxins of Hypoxylon mammatum and demonstration of some toxic effects on selected clones of Populus tremuloides. Phytopathology $74,654-658$ 